Check for updates

Cite this: Chem. Commun., 2020, 56,4720

Received 9th March 2020,

Accepted 18th March 2020

DOI: $10.1039 / \mathrm{d} 0 \mathrm{cc} 01810 \mathrm{~d}$

rsc.li/chemcomm

\section{Facile assembly of three cycloalkyne-modules onto a platform compound bearing thiophene $S, S$-dioxide moiety and two azido groups $\dagger$}

\author{
Tomohiro Meguro, Yuki Sakata, Takamoto Morita, Takamitsu Hosoya iD and \\ Suguru Yoshida iD *
}

\begin{abstract}
An efficient method to assemble three cycloalkyne-modules onto a platform compound bearing a thiophene S,S-dioxide moiety and two azido groups has been developed. The sequential reactions without catalysis or additives enabled the facile preparation of trifunctional molecules by a simple procedure. One-pot assembly was also achieved using the platform and three cycloalkynes.
\end{abstract}

Modular synthesis by consecutive reactions onto a platform molecule has gained attention as a facile method for preparing a wide variety of products from diverse modules. ${ }^{1,2}$ On the basis of the remarkable achievements by recently emerging click chemistry $^{3}$ including copper(I)-catalyzed azide-alkyne cycloaddition (CuAAC) ${ }^{4}$ and strain-promoted azide-alkyne cycloaddition (SPAAC), ${ }^{5,6}$ efficient assembly of modules by multi-click chemistry using well-designed platform molecules has been accomplished (Fig. 1). For example, Jiráček and coworkers achieved a triple-CuAAC reaction using platform 1 bearing terminal, triethylsilyl, and triisopropylsilyl alkynes through selective desilylprotonation (Fig. 1A). ${ }^{7}$ Triple-conjugation by tetrazine-norbornene ligation, CuAAC, and thiol-maleimide reaction using platform 3 developed by Knall and coworkers allowed for assembling threetypes of modules (Fig. 1B). ${ }^{8}$ Recently, we also developed a tris(triazole) formation method by three sequential reactions using platform 5 having three-types of azido groups. This method enabled to assemble three types of azidophiles having functional groups, such as HaloTag ligand, fluorescent, and biotin moieties (Fig. 1C). ${ }^{9}$ Despite these continuous efforts, an ideal method for assembling modules onto a platform molecule under catalysis-free conditions is not easy to develop due to the limited methods for reliable conjugation ${ }^{10}$ and difficulties to synthesize a platform molecule bearing discriminatable reactive groups. Herein, we describe an efficient method for highly

Laboratory of Chemical Bioscience, Institute of Biomaterials and Bioengineering, Tokyo Medical and Dental University (TMDU), 2-3-10 Kanda-Surugadai,

Chiyoda-ku, Tokyo 101-0062, Japan.E-mail: s-yoshida.cb@tmd.ac.jp

$\dagger$ Electronic supplementary information (ESI) available: Experimental procedures, characterization for new compounds including NMR spectra. See DOI: 10.1039/docc01810d
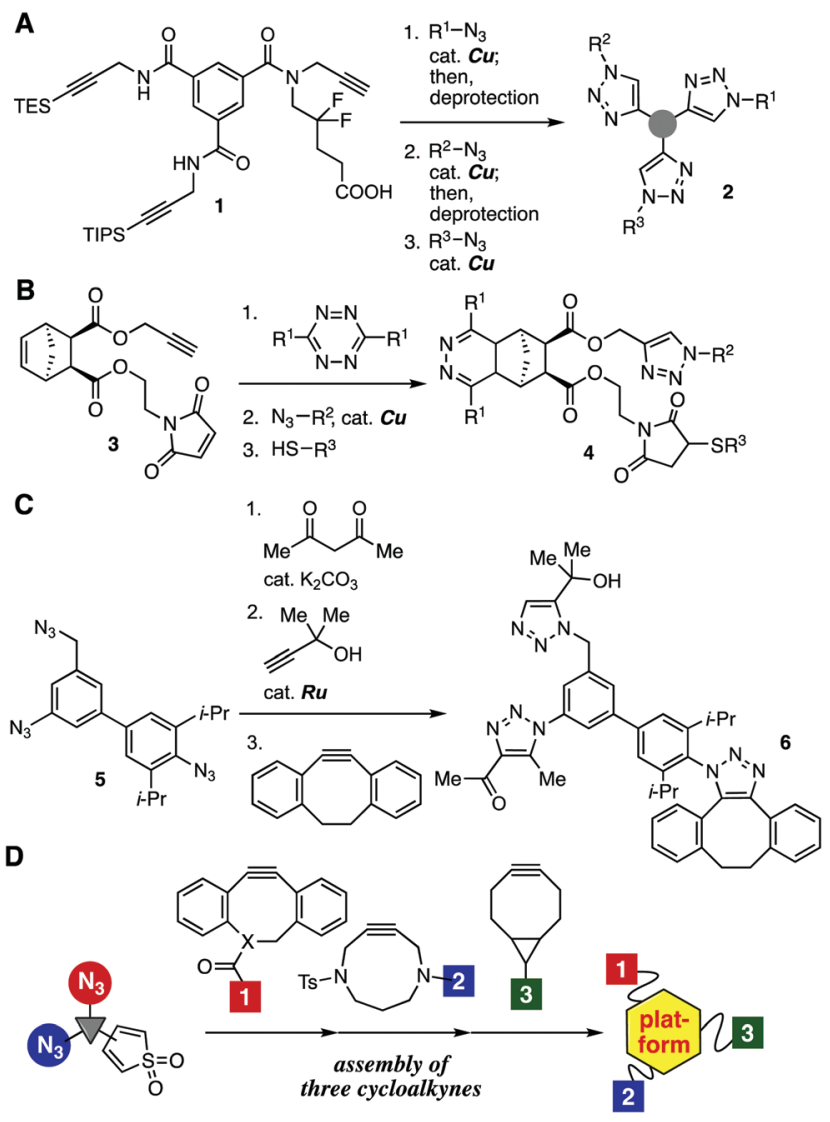

Fig. 1 Methods to assemble three modules onto a platform molecule. (A) Jiráček's work. (B) Knall's work. (C) Our previous work. (D) This work.

selective triple-conjugation of three cycloalkynes onto a newly designed platform bearing discriminatable thiophene $S, S$-dioxide moiety and two azido groups (Fig. 1D).

Focusing on the remarkable reactivities of cycloalkynes allowing for efficient conjugation under mild conditions without catalysis, we at first explored ynophiles with discriminatable 
A
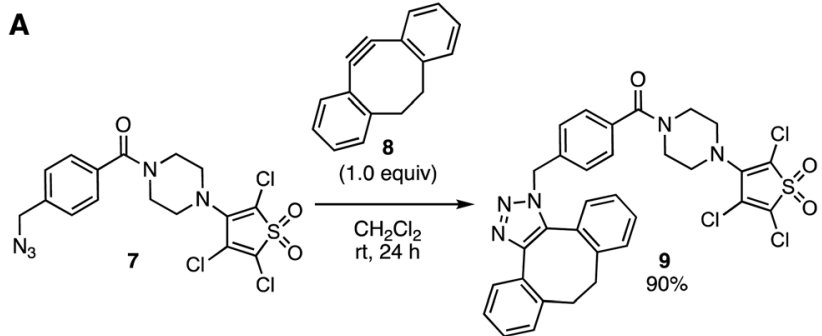

B
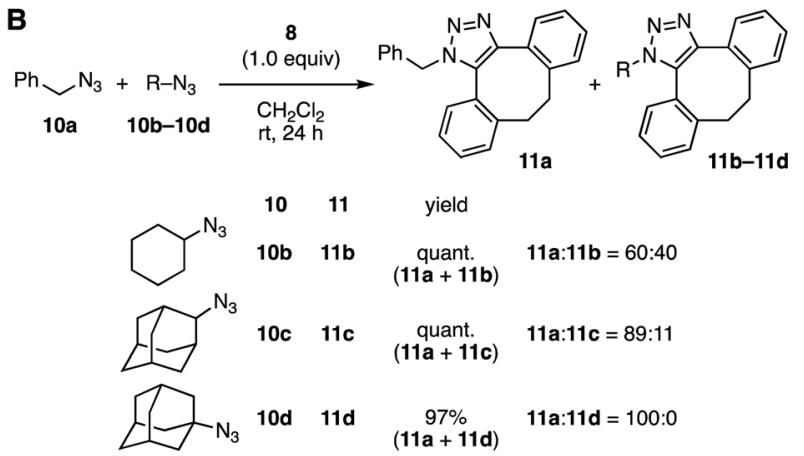

Fig. 2 SPAAC reactions between azides and dibenzo-fused cyclooctyne 8. (A) Selective reaction of platform 7. (B) Competition experiments using azides and cyclooctyne $\mathbf{8}$

reactivity (Fig. 2). Based on our previous report that 2,3,4,5tetrachlorothiophene $S, S$-dioxide slowly reacted with dibenzofused cyclooctyne 8 at room temperature, ${ }^{11,12}$ selective SPAAC reaction of cyclooctyne 8 with platform 7 proceeded smoothly at the benzyl azido group to provide triazole 9 leaving thiophene dioxide moiety untouched (Fig. 2A). We then envisioned that a bulky alkyl azide can remain intact in the SPAAC reaction of the benzyl azido group ${ }^{13,14}$ although the difference of the clickability between benzyl azide and phenyl azide in the SPAAC reaction was not satisfied. ${ }^{2 c, 6 f}$ Thus, a competitive SPAAC reaction of cyclooctyne 8 with an equimolar mixture between benzyl azide (10a) and bulky alkyl azide 10b, 10c, or 10d was examined (Fig. 2B). It was shown that the SPAAC of benzyl azide (10a) took place selectively when using 1-adamantyl azide (10d), while the selectivity was not satisfiable in the reaction of a mixture between secondary azide 10b or 10c and benzyl azide (10a). Furthermore, selective [2+3] cycloaddition between 1-adamantyl azide (10d) and thiophene dioxide 12 was accomplished by treatment with dibenzo-fused cyclooctyne $\mathbf{8}^{6 d}$ or 4,8 -diazacyclononyne (DACN) derivative $\mathbf{1 4}^{6 g}$ at room temperature without providing undesired products by the reaction of thiophene dioxide (Fig. 3). These results clearly showed that selective reactions of cycloalkynes with a platform having benzyl azide, 1-adamantyl azide, and thiophene dioxide moieties would proceed efficiently to furnish conjugated products without any undesired side products.

Having three discriminatable ynophiles in hand, we designed platform molecule 24 possessing these ynophilic moieties (Fig. 4). The synthesis of platform $\mathbf{2 4}$ was achieved from simple building blocks 17, 19, 21, and 23. Indeed, selective reduction at the aromatic azido group ${ }^{15}$ of diazide $17^{16}$ followed by amide formation using 3-azidoadamantane carboxylic acid (19) afforded diazide 20 in good yield. Then, transformations of methoxycarbonyl group to

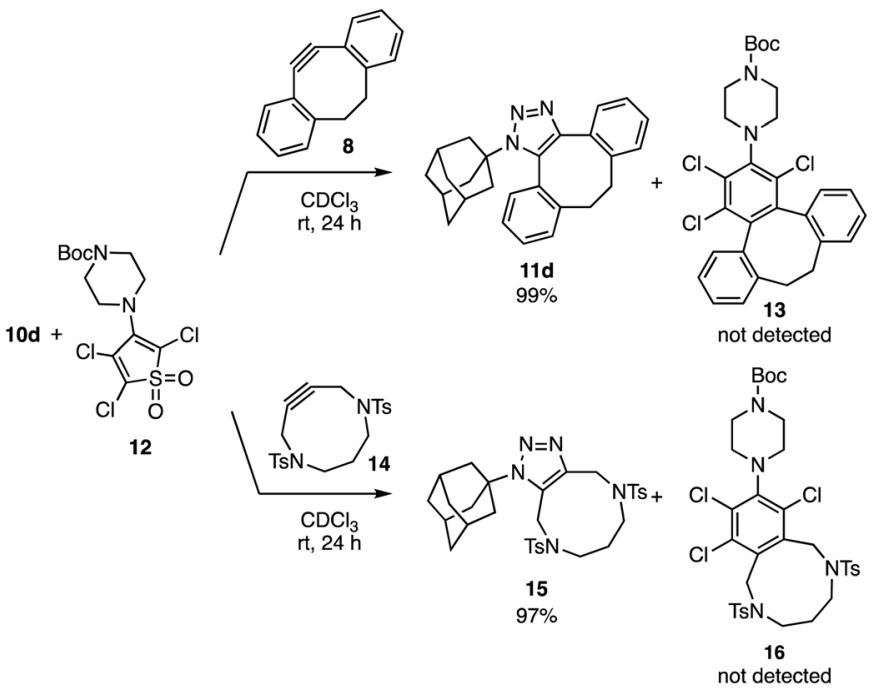

Fig. 3 Competition experiments treating a mixture of azide $10 \mathrm{~d}$ and thiophene dioxide 12 with cyclooctyne 8 or 14

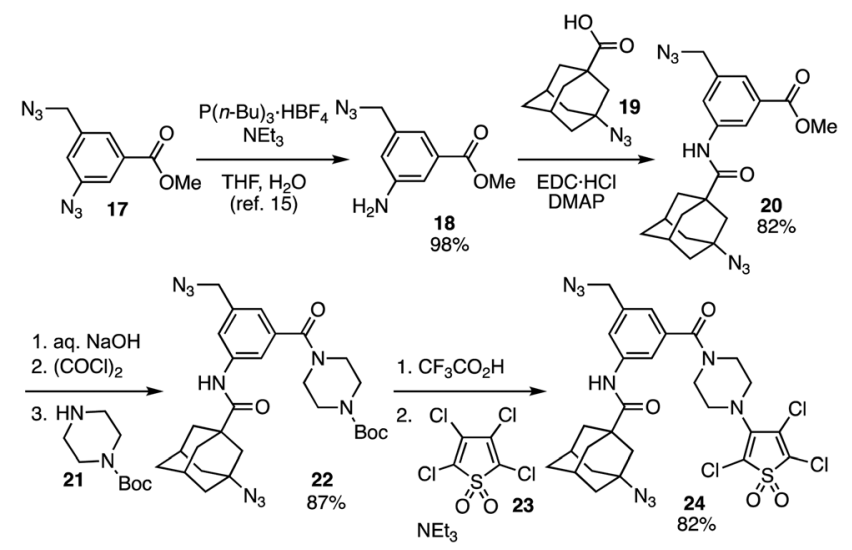

Fig. 4 Synthesis of platform 24. EDC = 1-(3-dimethylaminopropyl)-3ethylcarbodiimide. DMAP = 4-dimethylaminopyridine.

(4-(tert-butoxycarbonyl)piperazino)carbonyl group and subsequent removal of the tert-butoxycarbonyl group and substitution reaction with 2,3,4,5-tetrachlorothiophene $S, S$-dioxide (23) successfully provided platform 24 leaving two azido groups untouched.

Consecutive reactions using platform $\mathbf{2 4}$ with three cycloalkynes 8, 14, and 25 enabled efficient assembly to afford the desired conjugate 26 in a highly selective manner (Fig. 5). Indeed, SPAAC reaction of platform $\mathbf{2 4}$ with dibenzo-fused cyclooctyne 8 proceeded selectively as expected without reactions of 1-adamantyl azide or thiophene dioxide moieties (Fig. 5A). The remaining tertiary azide smoothly reacted with DACN derivative 14 with gentle heating and subsequent reaction between thiophene dioxide and bicyclo[6.1.0]non-4-yne (BCN) derivative $25^{6 e}$ took place efficiently. ${ }^{17}$ Thus, facile assembly by three consecutive catalysis-free reactions was achieved by the simple procedure without yielding any side products. Furthermore, one-pot assembly of the three components onto platform 24 successfully proceeded by sequential addition of cycloalkynes $\mathbf{8}$, 14, and 25 (Fig. 5B). ${ }^{18}$ 
A

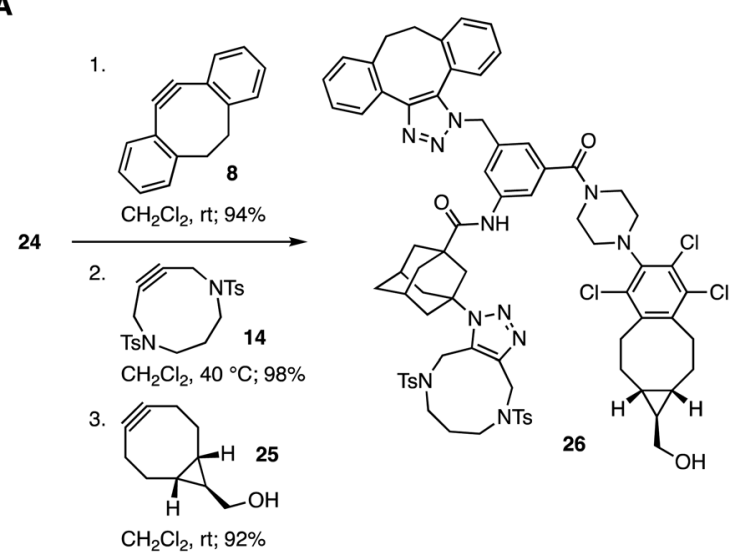

B

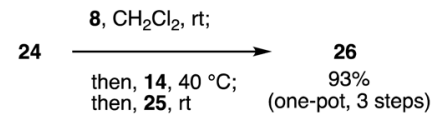

Fig. 5 Assembly of three cycloalkynes 8, 14, and 25 onto platform 24.

A

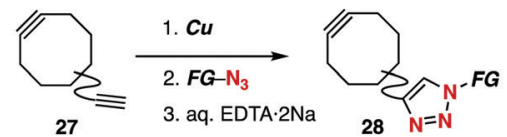

B

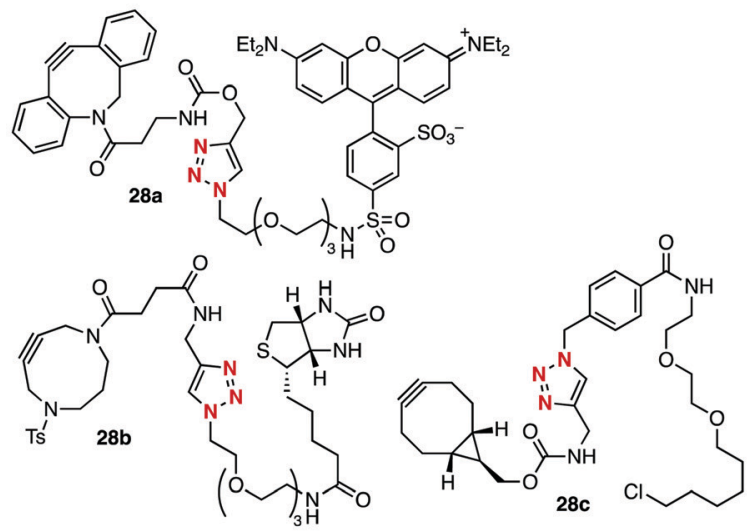

C

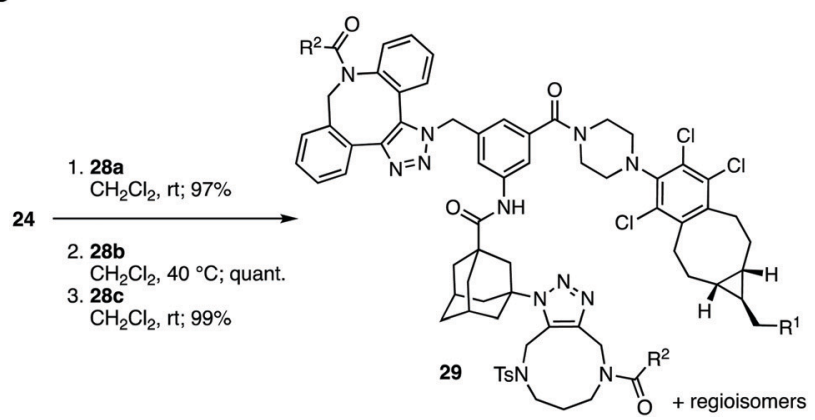

Fig. 6 Assembly of three cycloalkyne-modules. (A) Synthesis of cycloalkynemodules 28. (B) Structures of cycloalkyne-modules 28. (C) Assembly of functional cycloalkynes $\mathbf{2 8}$ onto platform $\mathbf{2 4}$. See the ESI $\dagger$ for the detailed structure of product 29. EDTA.2Na = ethylenediamine- $N, N, N^{\prime}, N^{\prime}-$ tetraacetic acid disodium salt.
To showcase the simplicity and efficiency of the method for preparing conjugates from cycloalkyne-modules, synthesis of trifunctional molecule $\mathbf{2 9}$ was demonstrated by assembling three functional cycloalkynes 28a-c onto platform 24 (Fig. 6). Three types of functional cycloalkynes 28a-c having a fluorescent rhodamine, biotinyl group, and ligand moiety for HaloTag, were successfully synthesized by CuAAC reactions on the basis of azide-to-cycloalkyne switching approach using the corresponding diynes 27 through transient protection of cycloalkyne moieties with copper (Fig. 6A and B). ${ }^{19}$ Then, these cycloalkynemodules, azadibenzocyclooctyne (DIBAC) derivative 28a, DACN derivative $\mathbf{2 8 b}$, and BCN derivative $\mathbf{2 8 c}$, were efficiently assembled to platform 24 in excellent yields as a mixture of regioisomers without damaging three functional moieties (Fig. 6C). Monitoring each step by HPLC analysis clearly showed the significant efficiency of this assembling method. ${ }^{17}$

In summary, we have developed an efficient method to assemble three cycloalkyne-modules using a platform compound having thiophene $S, S$-dioxide moiety and two azido groups. Since a broad range of functional cycloalkyne-modules are easily prepared by azide-to-cycloalkyne switching approach from easily available functional azides, this simple assembly method would serve in the preparation of various trifunctional molecules from easily available azide-modules. Further studies involving development of a thiophene dioxide-selective reaction of platform molecule $\mathbf{2 4}$ and application of this method are underway in our laboratory.

This work was supported by JSPS KAKENHI Grant Numbers JP19K05451 (C; S. Y.), JP18J11113 (JSPS Research Fellow; T. M.), JP18H02104 (B; T. H.), and JP18H04386 (Middle Molecular Strategy; T. H.); the Naito Foundation (S. Y.); the Japan Agency for Medical Research and Development (AMED) under Grant Number JP19am0101098 (Platform Project for Supporting Drug Discovery and Life Science Research, BINDS); and the Cooperative Research Project of Research Center for Biomedical Engineering.

\section{Conflicts of interest}

There are no conflicts to declare.

\section{Notes and references}

1 (a) A.-C. Knall and C. Slugovc, Chem. Soc. Rev., 2013, 42, 5131; (b) Z.-J. Zheng, D. Wang, Z. Xu and L.-W. Xu, Beilstein J. Org. Chem., 2015, 11, 2557; (c) S. Yoshida, Bull. Chem. Soc. Jpn., 2018, 91, 1293; (d) S. Yoshida, Org. Biomol. Chem., 2020, 18, 1550.

2 (a) I. E. Valverde, A. F. Delmas and V. Aucagne, Tetrahedron, 2009, 65, 7597; (b) B. C. Sanders, F. Friscourt, P. A. Ledin, N. E. Mbua, S. Arumugam, J. Guo, T. J. Boltje, V. V. Popik and G.-J. Boons, J. Am. Chem. Soc., 2011, 133, 949; (c) J. Dommerholt, O. van Rooijen, A. Borrmann, C. F. Guerra, F. M. Bickelhaupt and F. L. van Delft, Nat. Commun., 2014, 5, 5378; (d) P. R. Werkhoven, H. van de Langemheen, S. van der Wal, J. A. W. Kruijtzer and R. M. J. Liskamp, J. Pept. Sci., 2014, 20, 235; (e) M. Robert, J. Vallée, P. Majkut, D. Krause, M. Gerrits and C. P. R. Hackenberger, Chem. - Eur. J., 2015, 21, 970; $(f)$ R. R. Ramsubhag and G. B. Dudley, Org. Biomol. Chem., 2016, 14, 5028; $(g)$ D. A. Sutton, S.-H. Yu, R. Steet and V. V. Popik, Chem. Commun., 2016, 52, 553; (h) T. Meguro, N. Terashima, H. Ito, Y. Koike, I. Kii, S. Yoshida and T. Hosoya, Chem. Commun., 2018, 54, 7904; (i) T. Meguro, S. Yoshida, K. Igawa, K. Tomooka and T. Hosoya, Org. Lett., 2018, 20, 4126; $(j)$ T. Yokoi, H. Tanimoto, T. Ueda, T. Morimoto and K. Kakiuchi, 
J. Org. Chem., 2018, 83, 12103; (k) T. Yokoi, T. Ueda, H. Tanimoto, T. Morimoto and K. Kakiuchi, Chem. Commun., 2019, 55, 1891.

3 (a) H. C. Kolb, M. G. Finn and K. B. Sharpless, Angew. Chem., Int. Ed., 2001, 40, 2004; (b) C. S. McKay and M. G. Finn, Chem. Biol., 2014, 21, 1075; (c) J. Lahann, Click Chemistry for Biotechnology and Materials Science, John Wiley \& Sons, West Sussex, 2009.

4 M. Meldal and C. W. Tornøe, Chem. Rev., 2008, 108, 2952.

5 (a) M. F. Debets, C. W. J. van der Doelen, F. P. J. T. Rutjes and F. L. van Delft, ChemBioChem, 2010, 11, 1168; (b) J. C. Jewett and C. R. Bertozzi, Chem. Soc. Rev., 2010, 39, 1272; (c) E. M. Sletten and C. R. Bertozzi, Acc. Chem. Res., 2011, 44, 666; (d) S. Arumugam, S. V. Orski, N. E. Mbua, C. McNitt, G.-J. Boons, J. Locklin and V. V. Popik, Pure Appl. Chem., 2013, 85, 1499; (e) J. Dommerholt, F. P. J. T. Rutjes and F. L. van Delft, Top. Curr. Chem., 2016, 374, 16.

6 (a) N. J. Agard, J. A. Prescher and C. R. Bertozzi, J. Am. Chem. Soc., 2004, 126, 15046; (b) J. M. Baskin, J. A. Prescher, S. T. Laughlin, N. J. Agard, P. V. Chang, I. A. Miller, A. Lo, J. A. Codelli and C. R. Bertozzi, Proc. Natl. Acad. Sci. U. S. A., 2007, 104, 16793; (c) J. C. Jewett, E. M. Sletten and C. R. Bertozzi, J. Am. Chem. Soc., 2010, 132, 3688; (d) X. Ning, J. Guo, M. A. Wolfert and G.-J. Boons, Angew. Chem., Int. Ed., 2008, 47, 2253; (e) J. Dommerholt, S. Schmidt, R. Temming, L. J. A. Hendriks, F. P. J. T. Rutjes, J. C. M. van Hest, D. J. Lefeber, P. Friedl and F. L. van Delft, Angew. Chem., Int. Ed., 2010, 49, 9422; $(f)$ S. Yoshida, A. Shiraishi, K. Kanno, T. Matsushita, K. Johmoto, H. Uekusa and T. Hosoya, Sci. Rep., 2011, 1, 82; $(g)$ R. Ni, N. Mitsuda, T. Kashiwagi, K. Igawa and K. Tomooka, Angew. Chem., Int. Ed., 2015, 54, 1190; (h) S. Yoshida, J. Tanaka, Y. Nishiyama, Y. Hazama, T. Matsushita and T. Hosoya, Chem. Commun., 2018, 54, 13499.

7 (a) V. Vaněk, J. Pícha, B. Fabre, M. Buděšínský, M. Lepšík and J. Jiráček, Eur. J. Org. Chem., 2015, 3689; (b) B. Fabre, J. Pícha, V. Vaněk, I. Selicharová, M. Chrudinová, M. Collinsová, L. Žáková,
M. Buděšínský and J. Jiráček, ACS Comb. Sci., 2016, 18, 710; (c) B. Fabre, J. Pícha, V. Vaněk, M. Buděšínský and J. Jiráček, Molecules, 2015, 20, 19310.

8 A.-C. Knall, M. Hollauf, R. Saf and C. Slugove, Org. Biomol. Chem., 2016, 14, 10576.

9 S. Yoshida, K. Kanno, I. Kii, Y. Misawa, M. Hagiwara and T. Hosoya, Chem. Commun., 2018, 54, 3705.

10 E. M. Sletten and C. R. Bertozzi, Angew. Chem., Int. Ed., 2009, 48, 6974.

11 T. Meguro, S. Yoshida and T. Hosoya, Chem. Lett., 2017, 46, 1137.

12 Recent reports on transformations using thiophene $S, S$-dioxides, see: (a) W. Wang, X. Ji, Z. Du and B. Wang, Chem. Commun., 2017, 53, 1370; (b) S. Suzuki, T. Asako, K. Itami and J. Yamaguchi, Org. Biomol. Chem., 2018, 16, 3771; (c) T. Asako, S. Suzuki, K. Itami, K. Muto and J. Yamaguchi, Chem. Lett., 2018, 47, 968.

13 Selective click chemistry using bulky azides was presented in 2013, see: T. Morita, S. Yoshida, A. Shiraishi and T. Hosoya, 24th Symposium on Physical Organic Chemistry, Tokyo, Japan, September 5, 2013, Abstr., No. 1P038.

14 For recent examples of selective click conjugation using bulky azides, see: (a) N. Münster, P. Nikodemiak and U. Koert, Org. Lett., 2016, 18, 4296; (b) D. Svatunek, N. Houszka, T. A. Hamlin, F. M. Bickelhaupt and H. Mikula, Chem. - Eur. J., 2019, 25, 754.

15 T. Meguro, S. Yoshida and T. Hosoya, Chem. Lett., 2017, 46, 473.

16 S. Yoshida, Y. Misawa and T. Hosoya, Eur. J. Org. Chem., 2014, 3991.

17 While thiophene $S, S$-dioxides smoothly reacted with BCN-type cycloalkynes such as $\mathbf{2 5}$, the reactivity of thiophene $S, S$-dioxide with cycloalkynes $\mathbf{8}$ and $\mathbf{1 4}$ was low as reported in ref. 11 .

18 See the ESI $\dagger$ for details.

19 (a) S. Yoshida, Y. Hatakeyama, K. Johmoto, H. Uekusa and T. Hosoya, J. Am. Chem. Soc., 2014, 136, 13590; (b) S. Yoshida, T. Kuribara, H. Ito, T. Meguro, Y. Nishiyama, F. Karaki, Y. Hatakeyama, Y. Koike, I. Kii and T. Hosoya, Chem. Commun., 2019, 55, 3556. 